\title{
EDUCAÇÃO, CULTURA E PATRIMÔNIO DOCUMENTAL: POSSIBILIDADES E DESAFIOS DA EDUCAÇÃO PELO PATRIMÔNIO NO ARQUIVO PÚBLICO DA CIDADE DE BELO HORIZONTE
}

Michelle Márcia Cobra Torre ${ }^{1}$

\begin{abstract}
Resumo: O artigo tem o objetivo de discutir as possibilidades e os desafios da educação pelo patrimônio cultural em instituições arquivísticas, com base nas relações entre educação, patrimônio e identidade. A partir do exame de ações educativas realizadas pelo Arquivo Público da Cidade de Belo Horizonte (APCBH) pretende-se mostrar que os arquivos a partir de seu lugar institucional, de suas vivências e de seus debates próprios, são capazes de contribuir em processos educativos. Busca-se evidenciar que a relação entre o acervo documental e a sociedade se estabelece pelo diálogo entre o passado e o presente, assim como da apropriação da cidade, por meio de suas múltiplas relações entre o território e o acervo documental. Dentre as ações educativas desenvolvidas pelo APCBH, serão destacados dois projetos, a saber, 1) Uso de documentos em sala de aula; 2) Educação para o patrimônio cultural: formação de jovens mediadores e multiplicadores. As ações visam estabelecer o diálogo entre a instituição de guarda e a sociedade, de modo que essa atribua sentido ao acervo e se aproprie dele exercendo a sua cidadania.
\end{abstract}

Palavras-chave: educação; patrimônio cultural; arquivos; APCBH.

\section{EDUCACIÓN, CULTURA Y PATRIMONIO DOCUMENTAL: POSIBILIDADES Y DESAFÍOS DE LA EDUCACIÓN POR EL PATRIMONIO EN ARCHIVO PUBLICO DE LA CIUDAD DE BELO HORIZONTE}

Resumen: El artículo tiene el objetivo de discutir las posibilidades y los desafíos de la educación por el patrimonio cultural en instituciones archivísticas, basándose en las relaciones entre educación, patrimonio e identidad. Desde el examen de las acciones educativas realizadas por el Archivo Publico de la Ciudad de Belo Horizonte (APCBH) objetivase mostrar que los archivos, desde su lugar institucional, de sus vivencias y de sus debates propios, pueden contribuir en procesos educativos. El artículo pretende evidenciar que la relación entre el acervo documental y la sociedad ocurre por el dialogo entre pasado y presente, así como la apropiación de la ciudad, por medio de sus múltiples relaciones entre territorio y acervo documental. Entre las acciones educativas desarrolladas por el APCBH, serán destacados dos proyectos: 1) Educación para el patrimonio cultural: formación de jóvenes mediadores y multiplicadores; 2) Uso de documentos en clases. Las acciones objetivan establecer el dialogo entre la institución de guarda y la sociedad, de manera que esa atribuya sentido y utilice los acervos para el ejercicio de su ciudadanía.

Palabras clave: educación; patrimonio cultural; archivos; APCBH.

\footnotetext{
1 Doutora e pós-doutoranda em Estudos Literários pela Universidade Federal de Minas Gerais (UFMG). Responsável pelo Setor de Pesquisa, Difusão Cultural e Educação Patrimonial do Arquivo Público de Belo Horizonte. E-mail: michelletorre@yahoo.com.br.
} 


\title{
EDUCATION, CULTURE AND DOCUMENTARY HERITAGE: POSSIBILITIES AND CHALLENGES OF EDUCATION THROUGH HERITAGE IN THE BELO HORIZONTE CITY PUBLIC ARCHIVE
}

\begin{abstract}
The article aims to discuss the possibilities and challenges of education through cultural heritage in archival institutions, based on the relation between education, heritage and identity. From the examination of educational actions carried out by the Public Archive of the City of Belo Horizonte (APCBH) it is intended to show that the archives from their institutional place, their experiences and their own debates, are able to contribute to educational processes. It seeks to evidence that the relation between the documentary collection and society is established by the dialogue between the past and the present, as well as the appropriation of the city, through its multiple relations between the territory and the documentary collection. Among the educational actions developed by APCBH, two projects will be highlighted, namely: 1) Education for cultural heritage: training of young mediators and multipliers; 2) Use of documents in the classroom. The actions aim to establish a dialogue between the guard institution and society, so that it gives meaning to the collection and appropriates it by exercising its citizenship.
\end{abstract}

Keywords: education; cultural heritage; archives; APCBH.

Educação e cultura são dois pilares que devem estar em diálogo para a formação de sujeitos que sejam capazes de exercerem plenamente a sua cidadania. Se pensarmos na concepção de patrimônio cultural como os bens nos quais uma dada sociedade imprime significados, que são compartilhados ao longo das gerações, também concluímos que esses bens devem ser usufruídos pela sociedade, uma vez que geram sentido e conhecimento para a sua história e para as suas vivências. Dessa forma, o patrimônio cultural pode ser entendido como fonte para a constituição de identidades, e a forma como refletimos sobre ele, atribuindo-lhe diferentes significados, é essencial para a construção da nossa memória e identidade histórica.

Portanto, o reconhecimento desses elementos histórico-culturais como constituintes de identidades gera a consciência de que a responsabilidade de preservação pertence a toda a comunidade, bem como ao poder público. O exercício da cidadania está na conscientização dessa responsabilidade e na ação para a sua preservação, seja na comunidade, seja em demandas direcionadas ao poder público.

Nas relações entre o patrimônio cultural, as memórias e as identidades constituídas a partir desse diálogo ao longo das gerações, importa ressaltar o papel da educação como mediadora desses elementos. Acrescente-se que tal mediação pode dar-se pelo usufruto (pelos 
usos) do patrimônio cultural. Para isso, há diversos procedimentos que auxiliam na educação pelo patrimônio cultural com vistas à formação de sujeitos conscientes do exercício de sua cidadania.

Nesse contexto, o que as instituições arquivísticas têm a ver com a educação? O papel dos arquivos, em sua essência, é recolher, tratar, organizar e dar acesso à documentação que lhe é conferida para custódia. Porém, o desenvolvimento de outras atividades, sobretudo voltadas para o campo da educação, é capaz de reforçar os laços da instituição com a sociedade, de forma que os arquivos também passem a cumprir outro papel, de dimensão cultural e educacional. Contemporaneamente, os debates sobre as possibilidades de intervenções educativas em instituições arquivísticas têm ganhado corpo, devido à crescente demanda social por essas atividades, bem como ao adensamento das discussões no campo da Arquivologia.

Segundo Heloísa Liberalli Bellotto (2014), hoje os arquivos são reconhecidos pela sociedade como multifacetados, custodiando acervos diversificados e para fins variados, que permitem compreender as identidades culturais das comunidades, suas histórias e as relações entre os cidadãos e o Estado. Dessa forma, as funções desempenhadas pelos arquivos vão além das funções de organizar e conservar os documentos, e estão relacionadas à aproximação com o público em geral. Essas funções dizem respeito à cidadania e à busca da população por sua identidade cultural e o seu patrimônio histórico-cultural. Nesse sentido, "trata-se do uso popular do arquivo, especificamente, o do arquivo histórico, como detentor que é do patrimônio documental comum da sociedade na qual se insere" (BELLOTTO, 2014, p. 133). Ressalte-se a questão da mediação cultural que os arquivos podem exercer, em especial, em relação a ações voltadas para os públicos escolares.

Há múltiplas possibilidades de apropriações dos acervos custodiados pelos arquivos, que podem se realizar por meio de atividades culturais diversas como palestras, oficinas, exposições físicas ou virtuais, visitas mediadas, publicações, dentre outras. O diálogo do arquivo com a sociedade propicia a reflexão sobre o caráter educativo dos arquivos, assim como possibilita que novos públicos, para além dos pesquisadores, sejam atingidos pela instituição, sendo sensibilizados para a importância da preservação e da valorização do patrimônio documental da cidade, do estado ou do país. Desenvolver atividades que dialoguem com públicos diversos propicia que as instituições arquivísticas sejam consolidadas como espaços culturais, educacionais e de promoção da cidadania. 
O Arquivo Público da Cidade de Belo Horizonte (APCBH), instituição que será tomada para a reflexão deste trabalho, é um equipamento da Fundação Municipal de Cultura (FMC), que integra a Prefeitura de Belo Horizonte. A instituição foi criada em 1991, com o intuito de ser um instrumento de apoio à administração, à cultura e à história do município, preservando e dando acesso à documentação da cidade. O APCBH se destaca em termos de tratamento da informação, de conservação material dos documentos sob a sua custódia, por meio de seu modelo de digitalização, bem como por suas ações de educação patrimonial. Atualmente, o APCBH possui cerca de 1.500 metros de documentos textuais e 1 milhão e 200 mil itens documentais dentre fotografias, fitas de vídeo, cartazes, plantas, mapas, dentre outros.

A instituição recolhe documentos de caráter permanente, que são produzidos e recebidos pelas secretarias e órgãos municipais no âmbito da Prefeitura de Belo Horizonte. O APCBH também possui um convênio com a Câmara Municipal de Belo Horizonte desde 2005, realizando diversas atividades por meio dessa parceria. Também recebe documentação proveniente de doações, com documentos que possuem informações relevantes à história da cidade.

O APCBH promove a disseminação de seus conhecimentos metodológicos e técnicos para outras instituições arquivísticas, por meio de seminários e visitas técnicas, e para a sociedade, com o oferecimento de cursos e palestras, além da produção de publicações. $O$ acervo sob a sua custódia é consultado por diversos pesquisadores das mais variadas áreas do conhecimento, bem como é pesquisado pela comunidade para fins de comprovação de direitos.

Em seus diálogos com a sociedade, o APCBH também busca produzir exposições com os documentos sob a sua guarda, com o intuito de difundir o seu acervo, bem como, por meio de seu projeto de publicações, desenvolve materiais para divulgar o acervo, as metodologias arquivísticas empregadas na instituição e materiais de educação patrimonial. $\mathrm{O}$ APCBH mantém a Revista Eletrônica do Arquivo Público da Cidade de Belo Horizonte (REAPCBH), um periódico científico anual que contempla artigos, resenhas, ensaios e propostas pedagógicas de uso de documentos em sala de aula para diferentes níveis de ensino. O objetivo da revista é estimular a pesquisa e a reflexão científica sobre a cidade de Belo Horizonte, bem como sobre o campo de estudos arquivísticos, além de divulgar acervos documentais de diversas instituições. 
O Arquivo Público da Cidade de Belo Horizonte apresenta um conjunto de ações que compõem um programa educativo centrado no patrimônio documental da cidade. Desde o início da sua criação, desenvolve atividades de exploração de suas potencialidades educacionais que continuam sendo diversificadas e aprimoradas ao longo do tempo.

Articulando referências do campo da história e da educação patrimonial, o Arquivo vem promovendo ações educativas que colocam em evidência os procedimentos próprios da instituição no que se refere ao recolhimento e à conservação dos documentos, ressaltando o seu valor probatório, além de promoção da discussão sobre o Arquivo como patrimônio da cidade. Além disso, incorpora em suas práticas educativas os procedimentos metodológicos próprios do campo da produção do conhecimento histórico, como a leitura documental e o tratamento das fontes históricas como versões de experiências passadas.

A instituição utiliza o acervo para possibilitar a produção de reflexões acerca do patrimônio cultural, buscando divulgar o acervo documental e estimular o cidadão a interpretar e apropriar-se desse acervo. O APCBH possui um repertório amplo de atividades como as visitas a espaços do arquivo, a visita técnica, as oficinas, a visita monitorada com kit pedagógico e a proposta de leitura documental, as diversas publicações escritas e audiovisuais, como a cartilha educativa, a Coleção História de Bairros e o Vídeo documentário sobre o Arquivo, que evidenciam o esforço da instituição em se constituir em um espaço de memória comprometido com a sua função pública. Por meio de diferentes estratégias de ação educativa, que visam à formação de públicos, promove a democratização do acesso ao acervo documental do município, e convoca o público jovem a também ser responsável na preservação do patrimônio documental, seja público ou privado.

Desse modo, o trabalho de educação patrimonial desenvolvido pelo APCBH volta-se para o esforço de que seu acervo documental seja reconhecido como constituinte da identidade local de forma que os cidadãos belo-horizontinos atribuam significado a esse acervo entendo-o como patrimônio cultural.

Ao Arquivo Público da Cidade de Belo Horizonte interessa participar cada vez mais de ações culturais voltadas para a aprendizagem da história local e das identidades das comunidades locais, de forma que seu acervo seja reconhecido como patrimônio cultural e histórico. As ações de difusão cultural e educativas do APCBH objetivam construir um diálogo entre a vida cotidiana e o presente da cidade com o passado dessa sociedade, de forma crítica e reflexiva. Como arquivo municipal, o APCBH possui um acervo documental que diz respeito à cidade, bem como à história e à sociedade locais. Sendo assim, o patrimônio 
documental sob a guarda do APCBH possui várias possibilidades para ações voltadas para a cidade, para o território local, sua comunidade e sua história.

Ressaltamos que a concepção de educação pelo patrimônio cultural seguida pelo APCBH, tem como objetivo, para além da sensibilização e da conscientização da preservação e valorização do patrimônio documental, o uso de seu acervo com fins educativos. Nesse sentido, a instituição está de acordo com as considerações do historiador Ivo Mattozzi, no que diz respeito à metodologia do uso de bens culturais:

A primeira condição é que as experiências de aprendizagem se desenvolvam com a utilização dos bens culturais originais: monumentos, arquiteturas, fontes de arquivo, peças de museus, sítios arqueológicos, quadros autênticos, etc. A segunda condição é que sejam objeto de observação e de uso para produzir informações. A terceira condição é que esses sejam colocados em relação com o contexto e com a instituição que os tutela (MATTOZZI, 2008, p.149).

Para Ivo Mattozzi (2008), o território em que vivemos está repleto de marcas resultantes de fenômenos naturais e de ações humanas num processo interativo e dinâmico que se desenvolve ao longo do tempo. Como evidências de processos historicamente construídos, essas marcas podem assumir valor cognitivo, simbólico, afetivo e estético vindo a se constituírem em bens culturais. Esses bens culturais encerram, portanto, diferentes níveis de inteligibilidade: referente ao processo de sua produção e uso na sua origem; de descoberta e uso de conhecimento e o processo de sua valorização como bens culturais.

Interessado em analisar a relação entre os bens culturais e a história, esse autor, afirma que as marcas que se tornaram bens culturais, interessam à história na medida em que são transformadas em matéria-prima do conhecimento, em instrumentos de informação e em objeto de estudo histórico e, ao pertencerem ao território, tornam-se elementos de sua identificação. Assim os bens culturais são transformados em instrumentos de informação, tornando-se marcos do território e meios para o seu conhecimento. Tornam-se reconhecidos como parte de um patrimônio amplo e difuso sob a tutela de diferentes instituições. É importante salientar que "o escopo da educação patrimonial é gerar o sentido, o conhecimento e o respeito ao patrimônio" (MATOZZI, 2008, p.149). Essa geração de sentido e significado é o que define a atribuição de valor.

Ao analisar a relação entre a história e o patrimônio, Matozzi afirma que o patrimônio contribui para a construção da percepção e da visão histórica do território. A 
relação entre a história e o patrimônio na sua visão deveria ser caracterizada pelo contato direto com os bens, pela fruição cognitiva e estética, pela descoberta do valor simbólico e afetivo. Portanto, fazer a passagem do uso dos bens para a concepção do patrimônio seria, na visão de Mattozzi, a capacidade de reconhecer as razões do valor cultural do patrimônio, respeitando-o e preservando-o.

$\mathrm{O}$ APCBH, com base nas concepções acima descritas, acredita que a relação entre o acervo documental e a sociedade se estabelece por meio do diálogo entre o passado e o presente, da comparação entre o arquivo pessoal e o arquivo da cidade, assim como da apropriação da cidade, por meio de suas múltiplas relações entre o território e o acervo documental. Ao longo dos anos, a instituição esteve atenta à importância da história local, pois o APCBH é um arquivo que guarda a documentação referente à cidade e aos bairros. Como as primeiras experiências de vivências coletivas das pessoas se dão na cidade e nos bairros, é essencial para a instituição atentar para essa questão. Dessa forma, trabalhar com documentos referentes à cidade e aos bairros possibilita que haja uma identificação do estudante, pois esses são locais por onde eles circulam e vivem. Busca-se trazer documentos diversos possibilitando que se construa um entendimento mais amplo de como a cidade ou o bairro era antes e quais foram os percursos que levaram à configuração atual. Essa identificação e essa percepção histórica do território despertam questionamentos e a possibilidade de reflexão e de construção de memórias e de exercício da cidadania.

Dentre as ações de educação pelo patrimônio cultural, desenvolvidas pelo APCBH, destacamos dois projetos, a saber, 1) Uso de documentos em sala de aula; 2) Educação para o patrimônio cultural: formação de jovens mediadores e multiplicadores. As ações visam estabelecer esse diálogo entre a instituição de guarda e a sociedade, de modo que essa atribua sentido a esse acervo e se aproprie dele exercendo a sua cidadania.

O APCBH vem promovendo a oficina de uso de documentos em sala de aula, voltada para professores, do nível básico de ensino, e estudantes de graduação. A proposta de uso de documentos tem o intuito de incentivar o uso de acervos arquivísticos como recursos didáticos para o ensino de história, permitindo pensar a história como uma construção, feita a partir de seleções, segundo o olhar e os questionamentos de cada presente. Ainda, parte-se da concepção da história-problema tendo os documentos arquivísticos como fontes. A oficina tem o intuito de auxiliar o professor de ensino básico a desenvolver práticas pedagógicas de educação pelo patrimônio cultural, utilizando os documentos arquivísticos como recursos didáticos para o conhecimento histórico. Parte-se dos pressupostos de historiadores como 
Jacques Le Goff, Marc Bloch e Lucien Febvre, no que diz respeito à concepção de conhecimento histórico e de documento histórico para a construção da oficina.

Segundo o historiador Jacques Le Goff (2013), com a Escola dos Annales ou Nouvelle Histoire surgem novos problemas, novos métodos e novos objetos para a construção do conhecimento histórico. Assim, a história-problema não irá tratar de eventos, indivíduos e política, como se fossem dados objetivamente por meio dos documentos, mas sim de estruturas, conjunturas, coletividades, sociedades, economias, considerando-se a história como uma construção realizada pelo historiador. O historiador Marc Bloch define, na obra Apologia da História ou o Ofício do Historiador, a história não como a ciência do passado, pois, para ele, o passado não é objeto de ciência. A história também não poderia ser definida como a ciência do homem, mas sim poderia ser a ciência dos homens no tempo. A essas concepções junte-se a do historiador Lucien Febvre, que dizia a história ser filha de seu tempo. Assim, com a definição dos historiadores dos Annales sobre a história, é possível perceber uma intenção de problematizar o "fazer histórico", pois cada época terá suas perguntas, seus temas, suas inquietações. Dessa forma, presente e passado estão interligados e o historiador se dá conta de que cada época escreverá a história à sua maneira.

Outra discussão teórica que embasa a oficina de uso de documentos do APCBH é a concepção de "Documento/Monumento", de Jacques Le Goff (2001). Os materiais da memória coletiva e da história são os monumentos e os documentos, sendo que ambos estão relacionados com a questão do poder. De acordo com o historiador, o que sobrevive do passado não é o conjunto do que existiu no passado, mas uma escolha realizada por forças que operam no desenvolvimento temporal do mundo e da humanidade, bem como pelos que se dedicam ao estudo do passado. Deve-se ressaltar que há diferenças entre as denominações de documento ao longo da história, mas importa assinalar que o documento é um produto da sociedade que o fabricou, segundo as relações de forças presentes em determinada sociedade, sendo que o uso que se faz do documento pode transformá-lo em monumento. O documento pode se tornar monumento dependendo de sua utilização pelo poder. Nessa medida, o documento também é monumento, pois resulta do esforço de uma sociedade para impor ao futuro, de forma voluntária ou não, determinada imagem de si mesma. Desse modo, na oficina de uso de documentos do APCBH são abordados procedimentos metodológicos da pesquisa histórica que visam possibilitar aos alunos compreenderem qual o lugar social e institucional de produção dos documentos que estão sendo trabalhados. 
As considerações da historiadora e professora Circe Maria Fernandes Bittencourt (2011), na obra Ensino de História: fundamentos e métodos, também estão na base da concepção da oficina de uso de documentos do APCBH. Nessa obra, ela ressalta que o uso didático de documentos em sala de aula estimula o desenvolvimento intelectual e torna mais palpável um passado percebido como algo abstrato. $\mathrm{O}$ uso de fontes documentais possibilita aos estudantes a introdução ao pensamento histórico, levando a uma autonomia intelectual e à análise crítica da sociedade em uma perspectiva temporal. A autora salienta que o professor deve ter em mente a diferenciação do uso de documentos por um historiador e o uso para o ensino de história. Por exemplo, o documento pode ser usado pelo professor para suscitar uma situação-problema, ou seja, como um instrumento motivador da discussão. Importa ressaltar, segundo Bittencourt, que o uso de documentos em sala de aula facilita a compreensão do processo de produção do conhecimento histórico, bem como a percepção de que eles fazem parte da memória de uma sociedade.

O objetivo das oficinas de uso de documentos em sala de aula desenvolvidas pelo APCBH é pensar propostas pedagógicas de usos de documentos históricos envolvendo problematização, investigação e reflexão sobre o objeto. É de suma importância a abordagem de problemáticas da atualidade, de forma que passado e presente estejam em diálogo, buscando a geração de sentido e de novos significados para o patrimônio documental da cidade. Ressaltamos que para além da discussão sobre leitura documental e problematização do documento, também são trabalhadas com os professores as concepções de diferentes suportes, gêneros e formatos documentais. As oficinas são temáticas e partem de problemáticas atuais vivenciadas pela cidade, como, por exemplo, a questão da relação de Belo Horizonte com os rios, a mobilidade urbana, bem como outros temas relacionados ao cotidiano dos estudantes. São selecionados documentos que pertencem ao acervo do APCBH e pretende-se, com base nessa documentação, desenvolver competências de interpretação do patrimônio documental, levantar questionamentos sobre as mudanças ocorridas na cidade ao longo do tempo, as políticas públicas e as formas de intervenção que tanto cidadãos quanto poder público podem propor, buscando soluções e o exercício da cidadania.

Os documentos sob a guarda dos arquivos foram produzidos sem fins pedagógicos, e apenas pelo intermédio do educador eles se convertem em recursos didáticos privilegiados do ensino de história, de geografia e demais disciplinas. Segundo Miriam Hermeto e Mateus Henrique Pereira (2012), em estudo sobre a formação docente, há uma dificuldade dos estudantes de licenciatura em história em mobilizar os conhecimentos teórico-metodológicos 
na produção de material didático. As oficinas do APCBH se baseiam na premissa, tal como defendido pelos autores citados, de que é necessário estabelecer relações entre teoria e metodologia da história com as práticas de ensino. Ao utilizar os documentos arquivísticos como recursos didáticos há uma série de procedimentos que devem ser realizados, que se relacionam aos procedimentos de pesquisa histórica, com a construção de um problema, a leitura crítica das fontes e da historiografia, e a elaboração de uma narrativa com clareza da abordagem proposta pelo professor. Em uma articulação entre a metodologia da história e o ensino de história, deve-se pensar a pesquisa não como a busca por informações, mas sim como uma investigação, com questões e a formulação de um problema, a delimitação de um objeto, a leitura crítica de fontes variadas. Cabe ao professor, selecionar as fontes e elaborar questões, que orientam os estudantes, de acordo com o nível de ensino.

Nesse sentido, a oficina do APCBH tem o intuito de trabalhar com os professores e estudantes de licenciatura a questão da seleção dos documentos arquivísticos, pensando seus diferentes suportes, gêneros e formatos, além de atentar para a relação das práticas de ensino com a metodologia da história, discutindo questões como a escrita e a construção da história, bem como suas relações com a memória, o esquecimento e o poder. Conforme Hermeto e Pereira (2012, p.348), “além das questões pedagógicas e historiográficas, é preciso pensar em um processo de formação que se (pre)ocupe com uma melhor reflexão teórica, inclusive, que esteja disposto a enfrentar a relação entre ensino de história e teoria da história”. Dessa forma, deve-se pensar na aproximação do conhecimento histórico com as práticas cotidianas dos alunos, relacionando ensino de história com cidadania.

Para pensar em uma aproximação entre o ensino de história, o presente do aluno e a questão da cidadania, a proposta da oficina é baseada nos ensinamentos do educador e filósofo brasileiro Paulo Freire (2016), que nos mostra que ensinar exige respeito aos saberes dos educandos, assim, a escola tem o dever de respeitar os saberes socialmente construídos na prática comunitária, mas também, deve saber utilizar esses saberes relacionando-os ao ensino dos conteúdos. Ressaltamos como o problema e o objeto de investigação podem ser elaborados a partir da realidade cotidiana e do entorno dos estudantes. Vale destacar o que o educador diz em Pedagogia da autonomia:

Por que não aproveitar a experiência que têm os alunos de viver em áreas da cidade descuidadas pelo poder público para discutir, por exemplo, a poluição dos riachos e dos córregos e os baixos níveis de bem-estar das populações, os lixões e os riscos que oferecem à saúde das gentes. Por que não há lixões 
no coração dos bairros ricos e mesmo puramente remediados dos centros urbanos? (FREIRE, 2016, p.31-32)

Além dos ensinamentos de Paulo Freire, a oficina do APCBH também considera de suma importância o documento da Base Nacional Comum Curricular. Nela sugere-se que o professor trabalhe com os estudantes à luz da resolução de problemas, de questões, pensando no sujeito e no seu lugar no mundo. Pensar a agenda local e as especificidades de cada região também são pontos de interesse que aparecem no documento. Dessa forma, os estudantes devem ser instigados a conhecer o mundo em que vivem e serem agentes de transformação dessa realidade.

Nas oficinas de usos de documentos ofertadas pelo APCBH, os professores e os estudantes de licenciatura são instigados a construir propostas pedagógicas que serão levadas aos alunos em sala de aula. As propostas desenvolvidas nas oficinas incluem diversos procedimentos que podem ser usados em sala de aula com os documentos, que levem os alunos a compararem, a observarem, a descreverem, a interpretarem e a elaborarem sínteses e perguntas. Para isso, a oficina conta com uma rica variedade de documentos, de diversas linguagens, de suportes e formatos variados. O intuito de trabalhar com as fontes históricas é mostrar aos alunos que a interpretação histórica é uma construção social elaborada por homens em determinados momentos e contextos. Além disso, entende-se que os documentos só adquirem significado a partir dos olhares, questões e problemáticas que são colocadas, com o objetivo de estabelecer um diálogo entre presente e passado. Salientemos que o uso de documentos históricos como recurso didático possibilita ensinar história pautando-se na teoria e na metodologia da história.

Outra ação desenvolvida pelo APCBH com o uso de bens culturais é o projeto "Educação para o patrimônio cultural: formação de jovens mediadores e multiplicadores", que foi desenvolvido em 2013. O projeto surgiu devido à percepção de que cada vez mais a cidade é percebida em toda sua potencialidade educadora, sendo apropriada de diversas maneiras em processos de formação, que procuram se beneficiar do cenário urbano. Nesse contexto, o patrimônio cultural, em suas múltiplas formas, ganha papel ainda mais destacado como objeto de reflexão em processos educativos. Sendo assim, o projeto se propôs a refletir sobre possibilidades de apropriação, em práticas educativas, do patrimônio cultural belo-horizontino em seus múltiplos aspectos: arquitetônico, artístico, histórico, documental, iconográfico, dentre outros. 
O projeto consistiu em duas etapas: 1) elaboração de um material didáticoinformativo que contemplava as ações educativas de equipamentos da Fundação Municipal de Cultura (FMC), discutindo noções de educação patrimonial e propondo roteiros de apropriação da cidade, pensando educação e patrimônio belo-horizontino em seus múltiplos aspectos; 2) oferta de um curso de formação que possibilitou a discussão de vivências com o patrimônio cultural, das diferentes regionais da cidade, assim como a possibilidade de desenvolver práticas educativas com o patrimônio.

O projeto "Educação para o patrimônio cultural: formação de jovens mediadores e multiplicadores" contou com o patrocínio da Arcelor Mittal, via Lei Estadual de Incentivo à Cultura. A publicação foi produzida com base em uma ampla pesquisa nos acervos das instituições que compõem a Fundação Municipal de Cultura, e em discussões sobre os aspectos educacionais e patrimoniais da cidade, realizadas por uma equipe composta por especialistas de áreas distintas. Nessa obra, são descritas algumas das metodologias de educação patrimonial desenvolvidas por órgãos integrantes da Fundação Municipal de Cultura, com destaque para o Arquivo Público da Cidade de Belo Horizonte, a Diretoria de Patrimônio Cultural e o Museu Histórico Abílio Barreto.

Outra etapa do projeto consistiu na elaboração de um curso de formação de mediadores multiplicadores, que foi oferecido para as diferentes regionais da cidade de Belo Horizonte, no ano de 2013, sendo ministrado pela equipe do projeto. Após a conclusão desse projeto, pode-se dizer que os resultados ultrapassaram as expectativas iniciais, pois houve uma grande demanda em relação ao curso, bem como as discussões, empreendidas ao longo da formação de mediadores multiplicadores, resultou em uma rica troca de experiências, o que possibilitou formular novas reflexões sobre a educação patrimonial e a cidade.

A publicação levou ao conhecimento de um público amplo e diversificado as metodologias de educação patrimonial das instituições envolvidas no projeto e também propiciou refletir sobre a cidade e as possibilidades de sua apropriação nos processos educacionais, principalmente no que diz respeito à discussão de patrimônio cultural. Ao final da publicação, são apresentados os roteiros temáticos, que visam a uma reflexão sobre a cidade em seus múltiplos aspectos, discutindo-os como patrimônios a serem valorizados, apropriados e preservados pelos cidadãos belo-horizontinos. Os roteiros temáticos partem de questões do presente da cidade para propor discussões sobre seus diversos aspectos, com base em documentos do acervo do APCBH, objetos de museus da FMC, bem como questões atuais enfrentadas pela urbe. Os roteiros de apropriação da cidade são: Águas (rios), Áreas verdes 
(parques), Lazer (cafés e Pampulha), Memória construída (monumentos, estátuas, nomes de ruas, poesias), Modos de morar (conjuntos habitacionais, casa de fazenda, casas do Arraial, casas da nova capital, vilas e favelas), Mobilidade (meios de transporte ao longo do tempo, obras e viadutos), Religião (monumentos, igrejas, templos, terreiros), Escola (grupos escolares ao longo do tempo).

O curso de formação ofertado nesse projeto era gratuito e consistia na reflexão das potencialidades educativas do patrimônio cultural da cidade. O público inscrito era composto por professores (de diversos níveis de ensino), estudantes de graduação e jovens monitores da escola integrada. A carga horária do curso era de 4 horas semanais, totalizando 40 horas. A cidade de Belo Horizonte é dividida em nove regionais administrativas, que são formadas por bairros. Dessa forma, foram ofertadas nove turmas, com opções para manhã e tarde, em Centros Culturais da FMC e na sede do APCBH, contemplando assim diferentes regiões da cidade. O objetivo do projeto era que a formação possibilitasse aos mediadores a elaboração de oficinas voltadas para a educação patrimonial nas escolas e demais instituições, multiplicando saberes e construindo espaços de reflexão das práticas educativas e das potencialidades de apropriação da cidade.

No curso de formação, os alunos deveriam, como atividade de conclusão, abordar patrimônios culturais, imateriais ou materiais, aos quais se identificavam em suas regionais, propondo ações voltadas para a educação. Como o intuito do projeto era contribuir para a sensibilização de todos em relação à importância da abordagem da cidade como fonte educadora e permitir a multiplicação de ações nesse sentido, conclui-se que o projeto atingiu o que se propôs e permitiu que novos olhares fossem lançados sobre o diversificado patrimônio cultural da cidade, desvelando a sua potencialidade educadora.

Dessa forma, a instituição, no que diz respeito às suas ações de educação pelo patrimônio cultural, entende que o acervo sob a sua custódia, como um patrimônio de todos os cidadãos, deve ser usado (usufruído) por todos, como artefatos culturais que dizem da história do bairro, da cidade, que constituem a sua própria história, a sua identidade, mas também como forma de conhecerem seus direitos e deveres como cidadãos. O trabalho desenvolvido nos projetos de educação pelo patrimônio do APCBH visa a levar a sociedade a se reconhecer nesse acervo, identificando-se com essa história, relacionando suas memórias individuais às memórias da cidade, mostrando que as histórias que podem ser narradas por meio dos documentos do Arquivo fazem parte da história dessa sociedade. Assim, espera-se 
que a sociedade atribua sentido e valor a esse acervo entendendo-o como patrimônio cultural da sua cidade, do seu bairro.

Para além dessas atividades, há outras experiências que atingem e dialogam com a sociedade, de maneira informativa e reflexiva. As exposições, sejam físicas ou virtuais, colocam em evidência o acervo da instituição e disponibilizam para a comunidade sobretudo a escolar - uma seleção contextualizada de documentos históricos relacionados com temáticas atuais e relevantes para a sociedade.

O Arquivo Público da Cidade de Belo Horizonte já produziu diversas exposições físicas e virtuais baseadas em um trabalho de pesquisa profundo e reflexivo de seu acervo. A instituição possui um projeto de exposições, que é fruto de pesquisa de sua equipe técnica, que procura divulgar para a sociedade a riqueza e a diversidade do acervo que está disponível para consulta. Neste artigo, vale destacar a Série Exposições Virtuais Cartografia Histórica das Regionais de Belo Horizonte. A cidade de Belo Horizonte é dividida em nove regionais administrativas, formadas por bairros, que possuem características aproximadas, como forma de ocupação, por exemplo. O objetivo do projeto é produzir uma exposição para cada regional da cidade e levar a exposição para escolas de ensino fundamental.

As exposições podem ser vistas como uma oportunidade para estudantes e professores da educação básica conhecerem uma mostra de documentos de sua regional, bem como os principais marcos da ocupação do território da regional e as características do transporte, das habitações, das indústrias, do comércio e dos serviços que fizeram e ainda fazem parte da história da cidade, sendo importante para que a comunidade escolar possa fazer uma análise crítica da extensão e da efetividade da cidadania nesse espaço.

A seleção dos documentos é realizada no acervo do $\mathrm{APCBH}$, partindo-se de temáticas pertinentes aos problemas atuais da cidade, como moradia, transporte, meio ambiente, ocupação urbana, dentre outros. São selecionados cerca de cinco documentos cartográficos sobre cada temática e esses documentos dialogam com outros que são iconográficos ou textuais, de forma que professores e estudantes possam ter uma visão da variedade documental do acervo do $\mathrm{APCBH}$, além da oportunidade de trabalharem diversas linguagens.

Ressaltamos que no momento de desenvolvimento das ações que visam o diálogo com a comunidade escolar, é essencial que a instituição arquivística acompanhe as discussões relativas à educação e domine documentos importantes como os Parâmetros Curriculares 
Nacionais e a Base Nacional Comum Curricular, pois eles serão o suporte para a realização de procedimentos que sejam significativos para o público em questão.

Projetos como os que foram aqui apresentados podem ser considerados como ações que reforçam os laços de parceria entre as instituições arquivísticas e a comunidade escolar, na busca de difusão de conhecimentos e de formação de professores e estudantes que valorizem a memória, o patrimônio, a educação e a cultura das cidades. Defendemos que atividades assim, que se dediquem a uma aproximação entre os arquivos e as escolas tornemse cada vez mais constantes no cotidiano escolar, pois elas garantem às instituições arquivísticas um papel social de relevância para a construção da cidadania, bem como despertam nos jovens a sensibilidade e a consciência para a preservação dos acervos, que contam sobre a história de seu bairro e de sua cidade, ou seja, sobre uma história da qual ele também faz parte e se identifica.

Pelo exposto neste artigo, pode-se concluir que os arquivos são capazes de contribuir em processos educativos - escolares e não escolares -, agregando novas questões e novas abordagens a antigos problemas. Para que isso se realize, é fundamental que a instituição se compreenda não como único ator desses processos, mas como um dos participantes que desenvolve a cena. Para tanto, é preciso que a instituição arquivística reconheça os lugares sociais e as especificidades dos sujeitos com quem interage, bem como a legitimidade de suas diversas demandas. Além disso, que considere, ao projetar e desenvolver essas ações, as inúmeras mediações que perpassam os saberes por ela produzidos e, especialmente, as múltiplas possibilidades de apropriações dos acervos que custodiam.

Uma contribuição central da educação pelo patrimônio cultural para o desenvolvimento das ações educativas em arquivos é a compreensão de que o público-alvo da ação educativa, em última instância, são os sujeitos do processo de valorização e preservação dos bens culturais - e que esse processo é dinâmico e interminável. Os acervos documentais, como parte do patrimônio cultural de uma dada coletividade, não podem ser desvinculados desses sujeitos nos projetos educativos, tratados como objeto em si mesmos, com importância independente da relação que têm com suas comunidades de origem. Cultivar a relação entre esses dois polos - acervo e comunidade -, fortalecendo os elos de pertencimento e de identidade, pode contribuir para a atribuição de valor simbólico aos arquivos e para a ampliação do entendimento da noção de cidadania.

A importância de se pensar no processo de construção de capacidades de leitura de registros históricos - aqueles que constituem a essência dos acervos documentais - e 
possibilitar uma leitura mais densa e diversa da história regional e local são, por sua vez, contribuições fundamentais do ensino para o desenvolvimento de ações educativas nas instituições arquivísticas.

Ações que propiciem o uso didático do acervo sob a custódia dos arquivos possibilitam que essas instituições sejam vistas como fontes educativas, que possam informar e formar a comunidade, segundo suas demandas e projetos, o que também é uma oportunidade para que os arquivos contribuam de forma original e significativa desenvolvendo e apresentando novos materiais para a comunidade escolar, que poderá abordar temáticas diversas, para além da história e da geografia, dialogando com problemas atuais das cidades. Nos arquivos públicos, por exemplo, há diversos documentos sobre obras públicas relacionadas à mobilidade urbana e a serviços de infraestrutura como o saneamento básico, assim como obras e demandas da sociedade relativas ao meio ambiente. Temas como ocupação urbana, tipos de moradia, desenvolvimento industrial e econômico, abastecimento, saúde, educação, políticas públicas para moradores de rua, assim como festas e eventos diversos de uma região podem ser abordados com base na documentação encontrada em arquivos públicos.

As instituições arquivísticas podem pesquisar e relacionar esses conjuntos documentais, tornando-os disponíveis para a comunidade escolar. Um trabalho em parceria entre professores e técnicos de arquivos para a preparação desses materiais possibilitaria a troca de vivências, de informações e de abordagens pedagógicas muito mais ricas para os estudantes. A implantação de projetos de cooperação entre arquivos e escolas como laboratórios para o desenvolvimento de uso de documentos em sala de aula é um desafio que pode levar a bons resultados para a sociedade, que estará formando pessoas cada vez mais conscientes em relação aos seus deveres e direitos, ou seja, futuros cidadãos atuantes.

Os arquivos são fundamentais para a transmissão da cultura de uma sociedade e sua função está para além do uso administrativo e de pesquisas acadêmicas. Aproximar a comunidade dos arquivos envolve diversas ações no campo da educação pelo patrimônio cultural, pois também se pode considerar como função dos arquivos refletirem sobre sua condição patrimonial, o que envolve diversos sujeitos sociais e suas demandas cidadãs, numa dimensão ética, política, educativa e social.

\section{Referências}


BELLOTTO, Heloisa Liberalli. Arquivo: estudos e reflexões. Belo Horizonte: Editora UFMG, 2014.

BELLOTTO, Heloisa Liberalli. Arquivos permanentes: tratamento documental. 2.ed. São Paulo: T. A. Queiroz, 2004.

BITTENCOURT, Circe Maria Fernandes. Ensino de História: fundamentos e métodos. $4^{\mathrm{a}} \mathrm{ed}$. São Paulo: Cortez, 2011.

BLOCH, Marc. Apologia da história, ou, O oficio de historiador. Tradução André Telles. Rio de Janeiro: Zahar, 2001.

FREIRE, Paulo. Pedagogia da autonomia: saberes necessários à prática educativa. $54^{\mathrm{a} e d}$. Rio de Janeiro: Paz e Terra, 2016.

HERMETO, M; PEREIRA, M. H. de F. O ensino de história entre trajetórias e epistemologias: o desafio cotidiano de articular teoria e prática na formação do professor de história. Saeculum: Revista de História, João Pessoa, v.27, jul./dez. 2012.

LE GOFF, Jacques. História e memória. Tradução de Bernardo Leitão [et al.]. 7 ed. Campinas: Editora da Unicamp, 2013.

LE GOFF, Jacques. A História nova. Tradução Eduardo Brandão. 4 ed. São Paulo: Martins Fontes, 2001.

MATTOZZI, Ivo. Currículo de História e Educação para o Patrimônio. Educação em Revista, Belo Horizonte, n. 47, p. 135-155, 2008.

PELEGRINI, Sandra C.A. Patrimônio Cultural: consciência e preservação. São Paulo: Brasiliense, 2009. 